\title{
Classification of Stockwell Transform Based Power Quality Disturbance with Support Vector Machine and Artificial
}

\section{Neural Networks}

\author{
Ezgi Güney ${ }^{1 *(D)}$, Ozan Çakmak² (D), Çağrı Kocaman ${ }^{3}$ (iD \\ ${ }^{1}$ Sinop University, Vocational High School, Department of Electrical And Energy, Sinop, Turkey \\ ${ }^{2}$ Ondokuz Mayıs University, Vocational High School, Department of Electrical And Energy, Samsun, Turkey \\ ${ }^{3}$ Turkish Airlines Flight Management, İstanbul, Turkey \\ eguney@sinop.edu.tr, ozan.cakmak@omu.edu.tr, ckocaman@thy.com
}

\begin{abstract}
The detection and classification of power quality events that disturb the voltage and/or current waveforms in the electrical power distribution networks is very important to generate electrical energy and to deliver this energy to the end-user equipment at an acceptable voltage. Various property extraction methods are used to determine the type of disturbances in the electrical signal. In this study, seven power distortions including voltage sag, voltage swell, voltage harmonics, voltage sag with harmonics, voltage swell with harmonics, flicker, transient signals and pure sine as a reference signal is used. Synthetic data are produced in MATLAB using parametric equations based on TS EN 50160 standard. Four kinds of feature extraction as frequency-amplitude, time-amplitude, geometric mean and standard deviation is made with Stockwell Transform (ST), which is one of the methods used for the feature extraction of the determined GKB. Detection of voltage distortions is interpreted through these properties. 640 simulation data is entered into the classifier by using Support Vector Machines (SVM) and Artificial Neural Networks (ANN) and their classification performance is compared.
\end{abstract}

Keywords: Power Quality Disturbance, Stockwell Transform, Support Vector Machine, Artificial Neural Network.

\section{Stockwell Dönüşümü Tabanlı Güç Kalitesi Bozunumlarının Destek Vektör}

\section{Makinası ve Yapay Sinir Ağları ile Sınıflandırılması}

\section{Öz}

Elektrik enerjisi hizmetlerinin kesintisiz bir biçimde tüketiciye ulaştırılması büyük önem taşımaktadır. Sistemdeki bozulmaların tespiti ve alınması gereken önlemler bu açıdan önemlidir. Elektrik sinyalindekini bozulmaların türünün belirlenmesi için çeşitli özellik çıkarım yöntemleri kullanılmaktadır. Bu çalışmada, elektrik güç sistemlerinde meydana gelen Güç Kalitesi Bozunumlarından(GKB) gerilim yükselmesi, gerilim çökmesi, harmonikli gerilim, harmonikli gerilim düşmesi, harmonikli gerilim yükselmesi, flicker ve transient ile referans sinyali olarak saf sinüs sinyallerini içeren sekiz işaret toplam on dönem sürecek şekilde TS EN 50160 standartlarına göre MATLAB ortamında oluşturulmuştur. Belirlenen GKB'na ait özellik çıkarımı için kullanılan yöntemlerden biri olan StockwellDönüşümü ile frekans-genlik, zaman-genlik, geometrik ortalama ve standart sapma olmak üzere 4 çeşit özellik çıkarımı yapılmıştır. Bu özellikler üzerinden gerilim bozulmalarının tespiti yorumlanmıştır. Toplam 640 benzetim verisi Destek Vektör Makinaları (DVM) ve Yapay Sinir Ağları(YSA) ile sınıflandırıcıya sokularak sınıflandırma başarımları karşılaştırılmıştır.

Keywords: Güç Kalitesi Bozunumları, Stockwell dönüşümü, Destek Vektör Makinaları, Yapay Sinir Ağları.

\footnotetext{
* Corresponding Author.

E-mail: eguney@sinop.edu.tr
} 


\section{Introduction}

Today, power quality problems are an important issue for electrical energy services. In an electrical power system, the power reaching the end consumer must be clean. That is, it must be completely sinusoidal and the basic parameters of the network must be acceptable and within the limits set by the standards (Elango et al.,2016). Equipment used in power distribution are very sensitive to malfunctions in the supply systems (Singh et al., 1999). Power Quality (PQ) is vital to the smooth operation of power systems (Singh et al.,2017). The majority of the loads in the system are non-linear loads and cause system failure. These distortions produce results such as system resonance, capacitor overload and decrease in efficiency and changes in voltage magnitude (Dharavath et al., 2017). The main reasons for the deterioration in power quality are malfunction, load switching, capacitor switching, high switching frequency electronic devices, power converters, arc furnaces and transformers. Timely reducing of these distortions requires quick and accurate classification. It is of great importance to process and extract the signals for a successful classification. Some popular methods used for feature extraction of power quality are Short-Time Fourier Transform (STFT)(Azam et al.,2004, Ingale, 2014, Yoo et al., 2015) , Hilbert-Huang Transform (HHT) (Tao et al., 2013, Saxena et al., 2014), Wavelet Transform (WT) (Poisson et al., 2000, Gaing, 2004) and Stockwell Transform (S-transform) (Mahela et al., 2016, Raj et al., 2016, Zhao et al., 2016, Shamachurn, 2019, Liang et al., 2021). FT and STFT are not sufficiently successful in feature extraction. Although frequency analysis is performed well with FT, time information cannot be obtained (Zhao et al., 2016). STFT, which allows Fourier analysis by windowing in short time intervals for time information, is also not successful enough (Karasu, 2016). WT has been extensively used in feature extraction of power quality impairment. However, this method is greatly affected by electrical noise in the signal. S-transform is a time-frequency spectral localization technique proposed by Stockwell, which combines the features of WT and STFT. The Stransformation uses a window whose width decreases with frequency and provides a frequency-dependent resolution (Elango et al.,2016).

For classification, Artificial Neural Networks (ANN) (Agarwal et al., 2018), Support Vector Machine (SVM) (Ozgonenel et al., 2013, Thirumala et al., 2018, Choudhary, 2021), Fuzzy Logic (FL) techniques (Chilukuri et al., 2004, Mishra et al., 2021), Deep Learning (DP) methods (Wang et al., 2019, Sindi et al., 2021) are extensively used.

The aim of this study is to determine and analyze the PQDs of power systems in a strong- reliable way with the S-transformation, and detect the most suitable classifier. For this purpose, firstly, seven different PQDs are created in MATLAB environment including voltage sag, voltage swell, transient at different amplitude, duration and angles, and voltage harmonic, voltage sag with harmonic, voltage swell with harmonic and flicker at different time and frequency. Sampling frequency is taken $25.6 \mathrm{kHz}$. Pure sine signal is selected as reference. The obtained waveform feature extraction is made by $\mathrm{S}$ transformation. A total of 640 simulation data are obtained from the S-transformation of the signals for Amplitude-Time, Amplitude-Frequency, Geometric Properties, Standard Deviation Properties. Using these features, the success of classification of PQD is investigated with SVM and ANN.

The paper is organized in four sections. Section 1 gives a basic introduction to the topic. Section 2 describes the S-Transform and feature extraction technique according to types of power quality disturbances. Section 3 presents the achieved test results and discussion. In this section, classification techniques based on SVM and ANN are elaborated. Section 4 presents conclusion.

\section{Materials and Methods}

\subsection{S-Transformation}

First, The S-transform was defined by R. G. Stockwell and was derived from the continuous wavelet transform. This transformation includes both amplitude and phase spectrum information together (Raj et al., 2016). S-transform is a method that involves both shorttime Fourier transform and wavelet analysis but falls into a different category (Cortes et al., 1995). The wavelet transform cannot yield significant results in noisy

environments, while the S-transform provides successful results in property extraction in the presence of noise. This makes S-transformation suitable for accurate detection and classification of power quality disturbances.

The S-transform uses an analysis window that decreases in width depending on frequency and provides a frequency-dependent resolution. The time-frequency spectrum of the modulated signal is focused. The timefrequency analysis technique provides a threedimensional graph of a signal in terms of signal energy or magnitude of time and frequency (Zhao et al., 2016).

The general S-transform is defined by Equation (1).

$$
s(\tau, f)=\int_{-\infty}^{\infty} x(t) g(\tau-t, f) e^{-j 2 \pi f t} d t
$$

$\mathrm{x}(\mathrm{t})$ is the signal and $\mathrm{g}(\mathrm{t})$ is the windowing function. The window function is a modulated Gaussian function expressed by Equation (2).

$$
g(\tau)=\frac{|f|}{\sqrt{2 \pi}} e^{-\left(t^{2} f^{2} / 2\right)}
$$

The general equation is; 


$$
(\tau, f)=\int_{-\infty}^{\infty} x(t) \frac{|f|}{\sqrt{2 \pi}} e^{-\left((\tau-t)^{2} f^{2} / 2\right)} e^{-j 2 \pi f t} d t
$$

After obtaining the S-transform, four different properties are extracted. The first property is the amplitude-time property obtained by taking the largest values of the lines of the S-transformation. This feature provides information about the amplitude of the signal. The second feature is the frequency-amplitude property obtained by taking the largest value of the columns of the S-transformation. This feature provides information about the frequency of the signal. The third feature is the geometric mean of the S-transformation. This feature helps to locate sudden amplitude changes in the signal. The last feature is obtained by taking the standard deviation. This provides the same information as the time-amplitude property, but is additionally used to detect the harmonics in the signal.

\subsection{According to Disturbances Types of Signals $S$-Transformation and Feature Extraction}

The healthy simulation model operates at $1 \mathrm{pu}$ voltage amplitude. Sampling frequency is $25.6 \mathrm{kHz}$. PQD are produced as 5120 samples in 10 period's length.

\subsubsection{Pure Signal}

The pure sine signal and its S-transformation graphs are given in Figure 1. Frequency-amplitude, timeamplitude, geometric mean and standard deviation characteristics obtained from S-transform of pure sine signal are given in Figure 2.
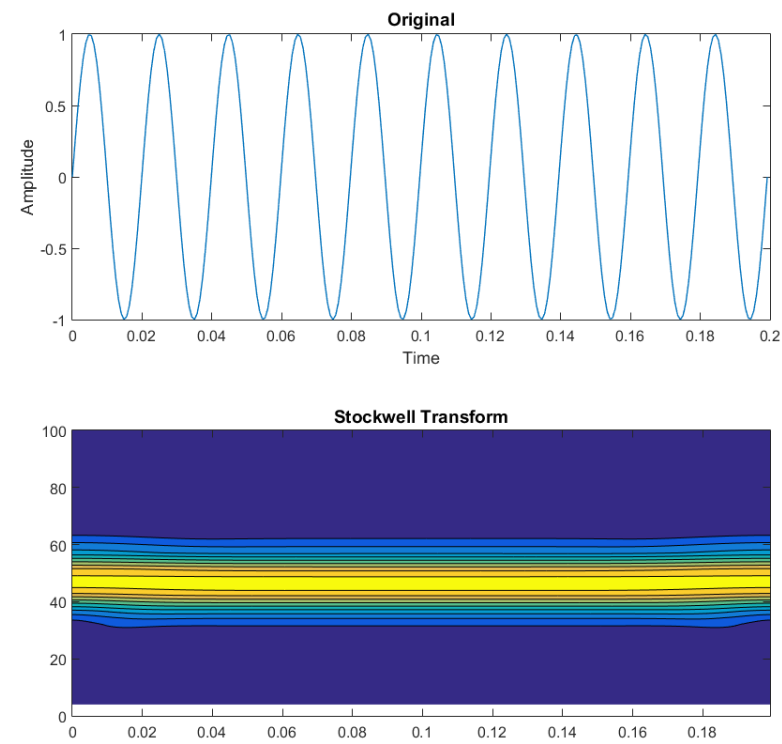

Figure 1. Pure Sine signal and S-transformation

The amplitude-time graph, which gives information about the amplitude of the signal, shows that the amplitude is constant and does not change over time. In the amplitude-frequency graph, it is seen that only $50 \mathrm{~Hz}$ network frequency is available. Since the periodicity of the signal is not disturbed, no change is observed in the graph of the geometric mean. In the standard deviation graph, we obtain information about the amplitude of the signal as in the amplitude-time graph, but unlike the first feature, we can also observe periodic fluctuations from this graph.
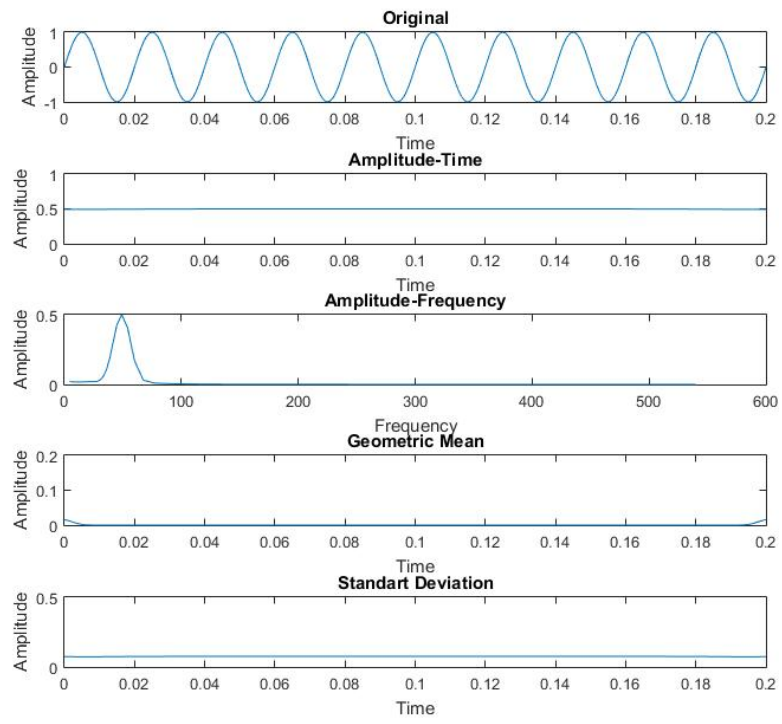

Figure 2. Properties derived from S-transformation of pure sine

\subsubsection{Voltage Sag}

Voltage sag is defined as the decrease in the mains voltage nominal value between $10-90 \%$. The graph and $\mathrm{S}$-transform of a 10-period mains voltage signal with a $50 \%$ voltage sag between the 2 nd and 6th periods are given in Figure 3.

The frequency-amplitude, time-amplitude, geometric mean and standard deviation characteristics obtained from the $\mathrm{S}$-transform of the voltage sag signal are given in Figure 4.
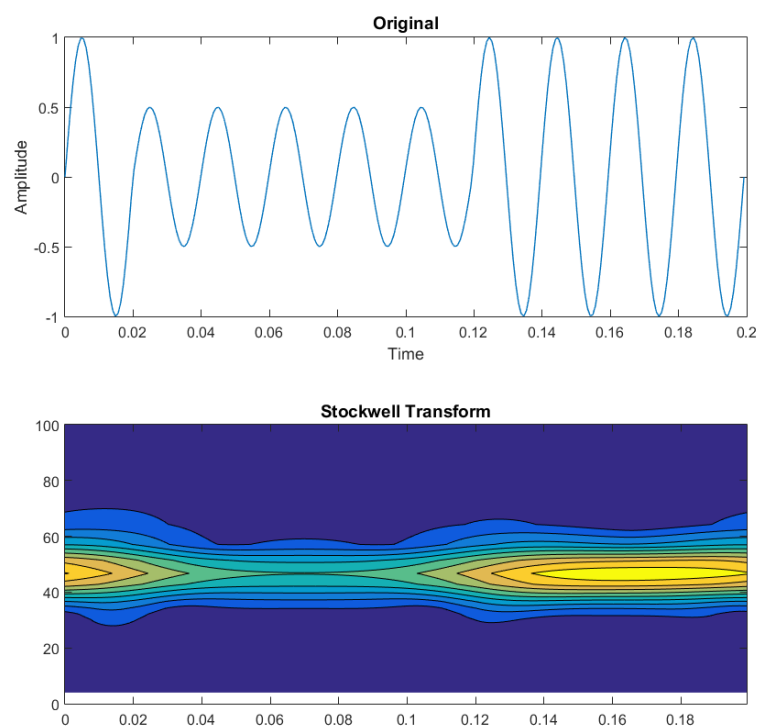

Figure 3. 50\% voltage sag signal and S-transform 

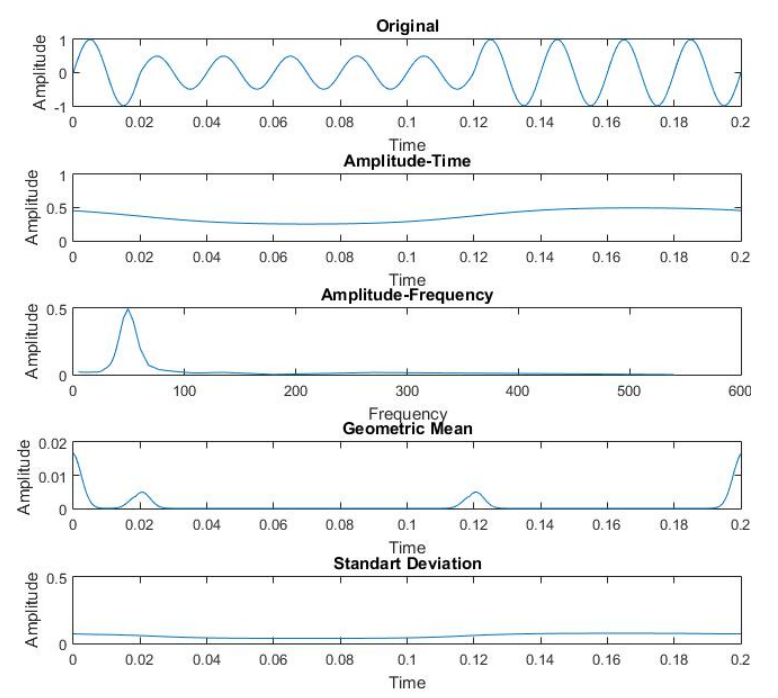

Figure 4. Characteristics obtained from S-transform of $50 \%$ voltage sag signal

As seen in the amplitude-time graph, which is the first feature, the amplitude decreased between the 2nd and 6th periods. This decrease is also seen in the standard deviation graph. Since there is no change in frequency, there is no difference in amplitude-frequency graph compared to pure sine. In the geometric mean graph, the location of the changes in the original signal on the time axis is revealed. The graph has changed at the beginning of the 2 nd and 6 th periods.

\subsubsection{Voltage Swell}

Voltage swell is defined as the increase of the mains voltage nominal value to $110-180 \%$. The graph and Stransform of a 10-period mains voltage signal with a $150 \%$ voltage swell between the 2 nd and 6th periods are given in Figure-5. The characteristics of the voltage swell signal are given in figure 6 .
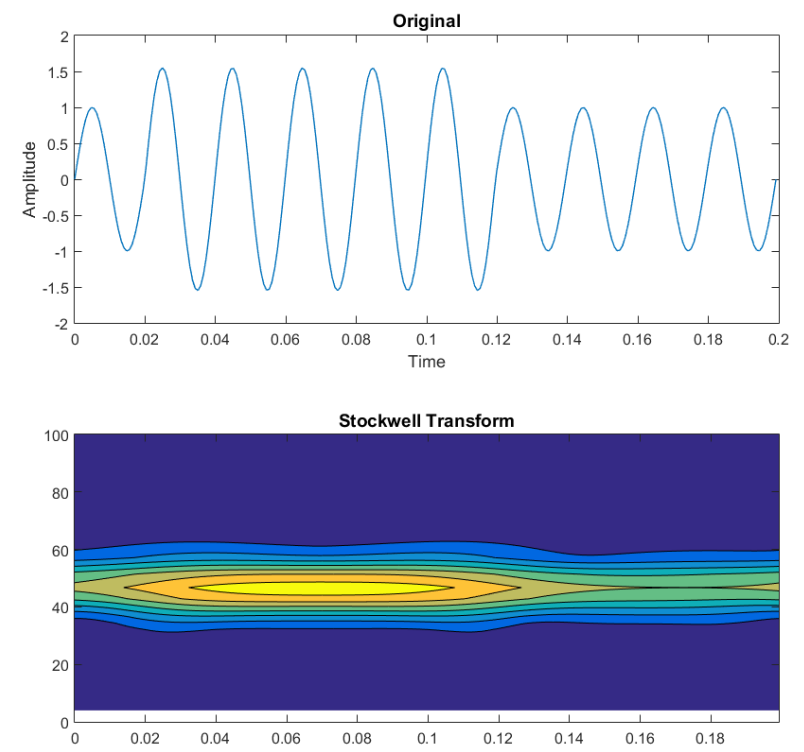

Figure 5. 50\% voltage swell signal and Stransform
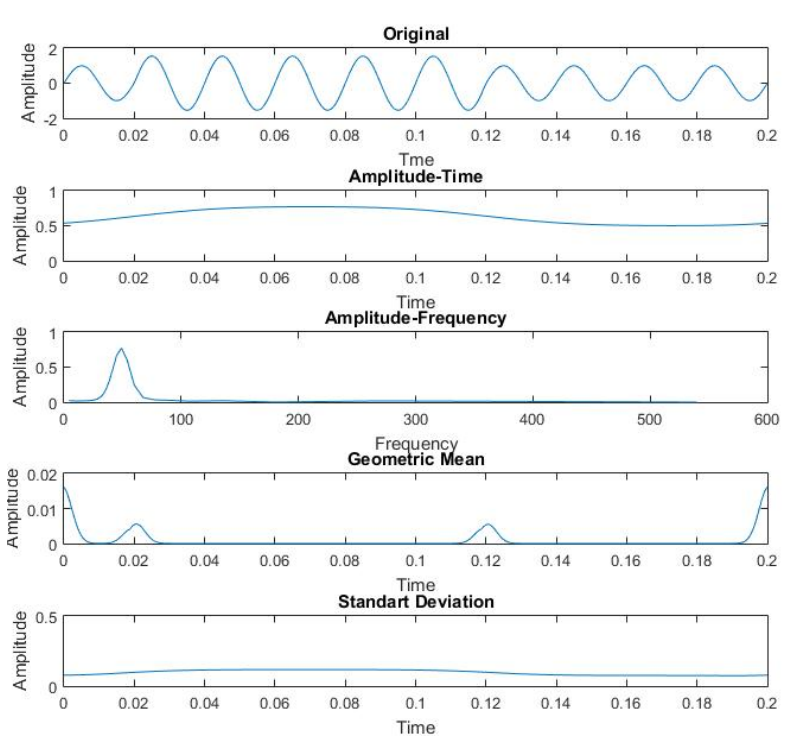

Figure 6. Characteristics obtained from the S-transform of $80 \%$ voltage swell signal

On the amplitude-time graph, the amplitude increased between the 2 nd and 6 th periods. The frequency-time graph shows that only a frequency of 50 $\mathrm{Hz}$ is present. On the other hand, the geometric mean graph shows the change in the original signal at the beginning of the 2nd and 6th periods, which are the place of the changes in the time axis.

\subsubsection{Flicker}

Voltage flickers under the frequency of $50 \mathrm{~Hz}$, which are caused by fluctuations in the flicker load and cause flickering in lighting. In the standards, flicker intensity limit values are given between 0.8 and 1. In Figure 7, 0.8 flicker voltage signal and S-transform are given. The properties obtained from S-transformation for this disturbance are given in Figure-8.
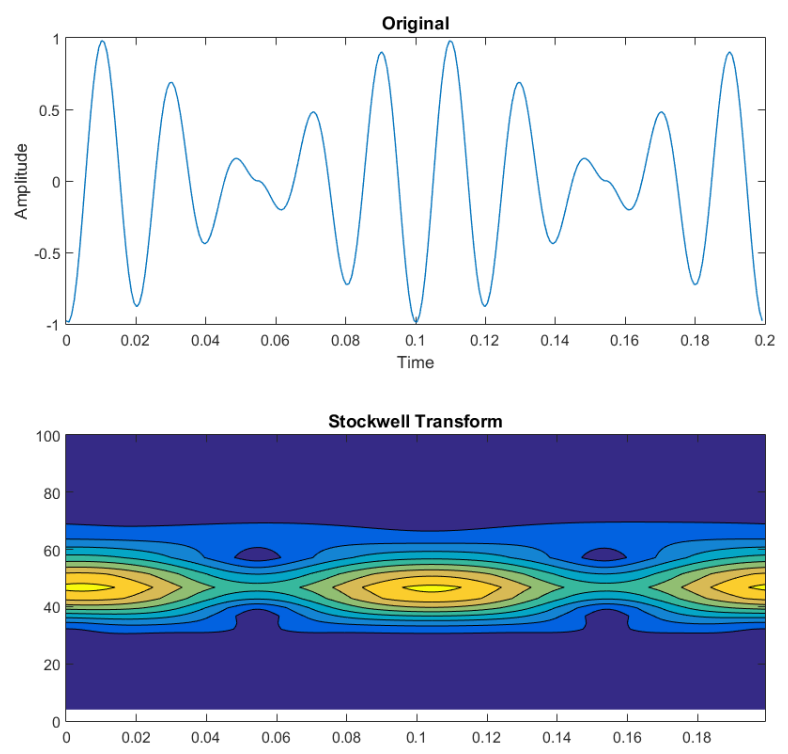

Figure 7. Voltage signal and S-transform with flicker intensity limit value 0.8 

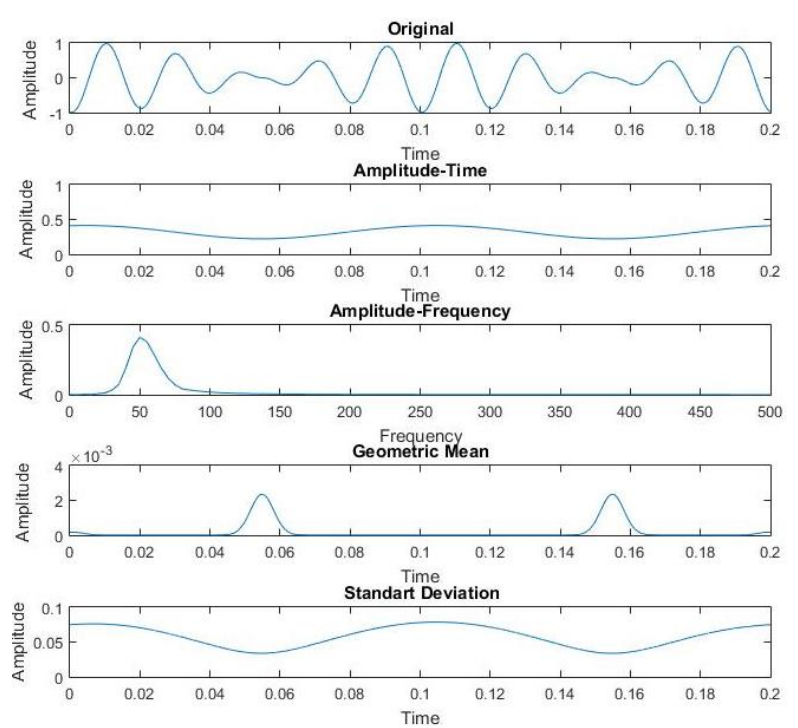

Figure 8. Properties of the S-transform of the voltage signal with a flicker intensity limit value of 0.8

The amplitude time graph shows the decrease in the voltage caused by the flicker. The amplitude frequency graph shows a $50 \mathrm{~Hz}$ sine signal. In the feature graph extracted from the geometric mean, the times when flicker is realized become apparent in the 3rd and 8th Periods. Since there are no different frequencies in the signal, only the voltage variation is observed in the standard deviation graph.

\subsubsection{Transient}

This is called a temporary change in the power system that takes place from $50 \mathrm{~ns}$ up to $50 \mathrm{~ms}$. The distortion voltage of $4 \mathrm{kHz}$ in the $3 \mathrm{rd}$ and 6th periods and the S-transform are given in Figure-9. Figure-10 shows the properties extracted from the $\mathrm{S}$ transformation of this signal.
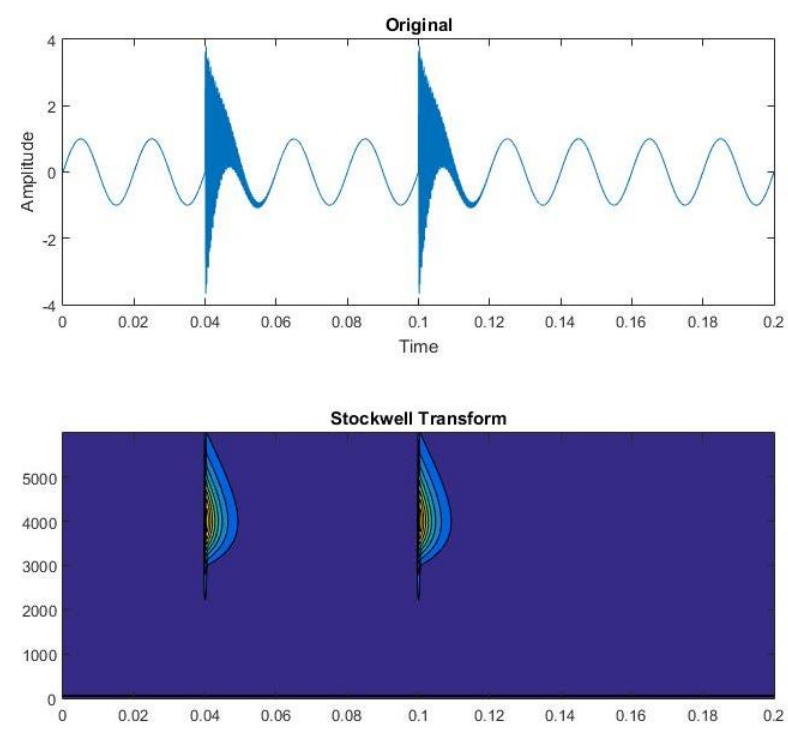

Figure 9. Transient signal and S-transform of power quality disturbance
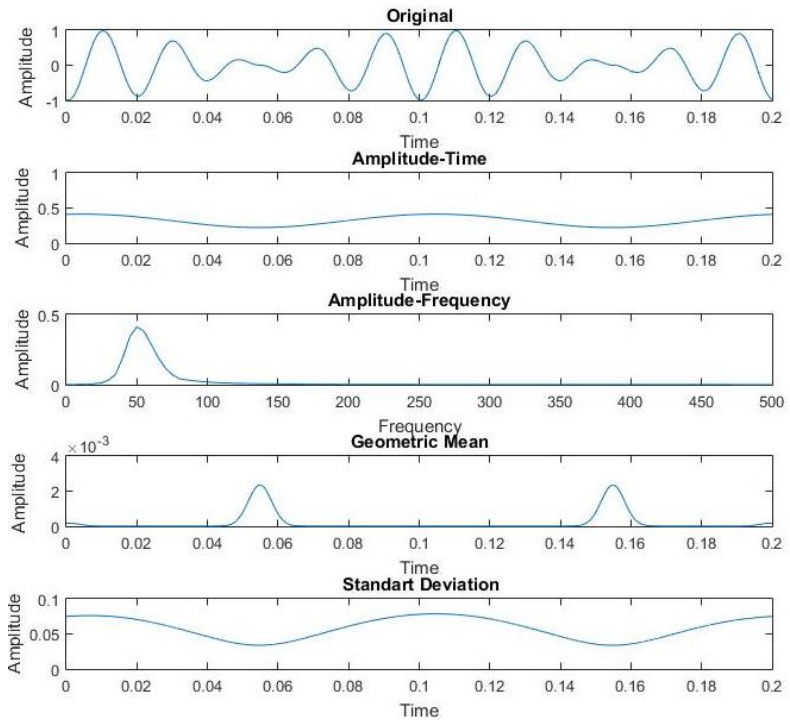

Figure 10. Features derived from S-transformation of transient power quality disturbance

The amplitude time graph shows the parts where the voltage rises. The $50 \mathrm{~Hz}$ signal and the transient signal present in the signal are plotted on the amplitudefrequency graph. The geometric mean graph gives the starting points of the transient signals. Finally, the standard deviation graph shows the change along the transient along with the amplitude change.

\subsubsection{Voltage with Harmonics}

It is the distortion of the voltage or current waveform from the ideal sine. The signal containing the 3rd and 5 th harmonics in the 10-period signal and the $\mathrm{S}$ transformation of this signal are given in Figure-11.

S-transformed properties of harmonic voltage are given in Figure-12.
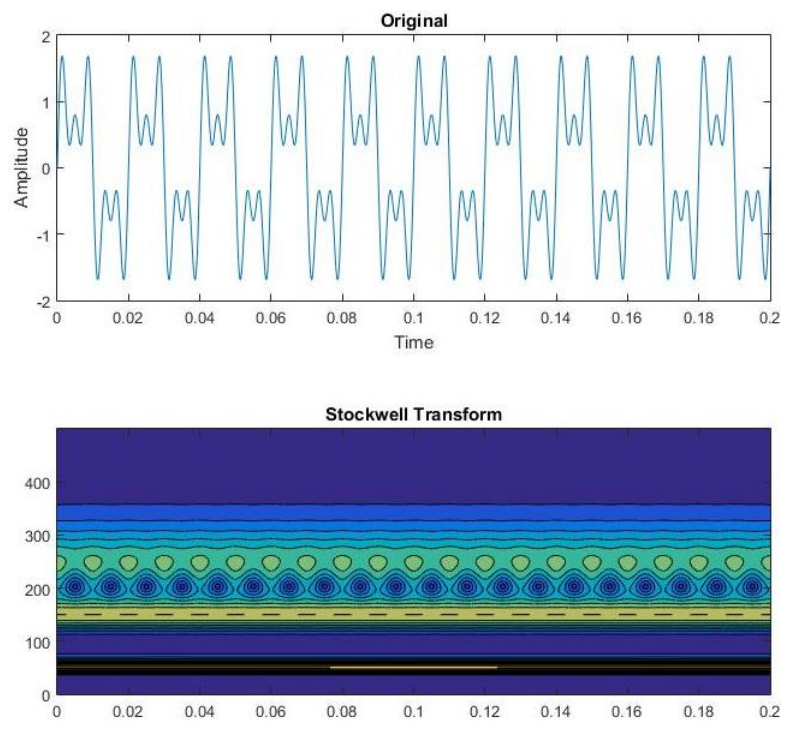

Figure 11. The 3rd and 5th harmonic added voltage signal and S-transform 

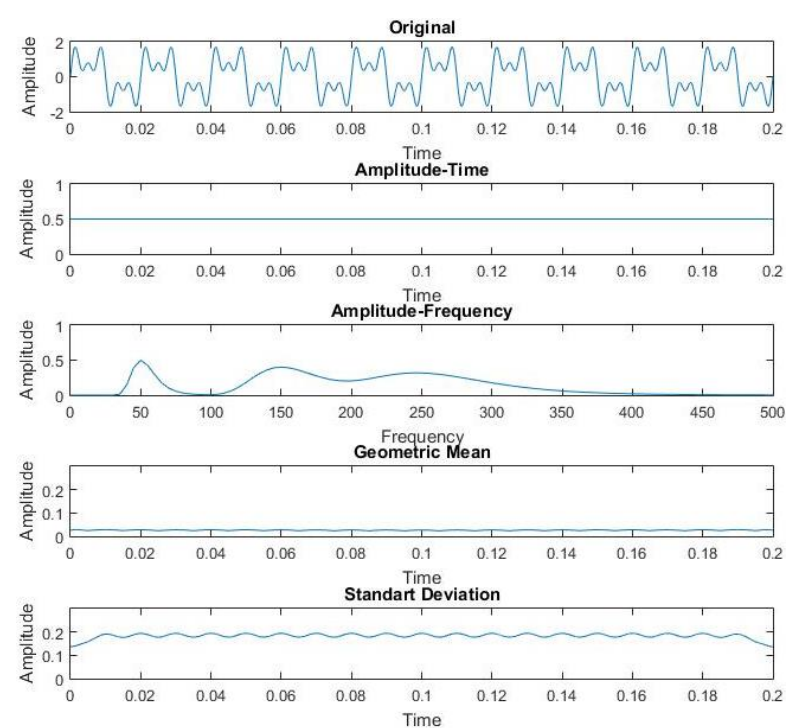

Figure 12. Properties obtained from S-transform of the 3rd and 5th harmonic added voltage signal

The amplitude-time plot is constant since no voltage decrease or increase in the periodic signal occurs. In the amplitude-frequency graph, the 3rd and 5th harmonics in the signal are seen as $150 \mathrm{kHz}$ and $250 \mathrm{kHz}$. On the other hand, since the amplitude changes due to the 3rd and 5th harmonics are small, no significant change was observed in the geometric feature graph. In the standard deviation feature, fluctuations due to harmonic can be observed.

\subsubsection{Voltage Sag with Harmonics}

The 10-period signal contains the 3rd and 5th harmonics, as well as the voltage sag during the 2 nd and 6th periods and the S-transform is given in Figure-13.
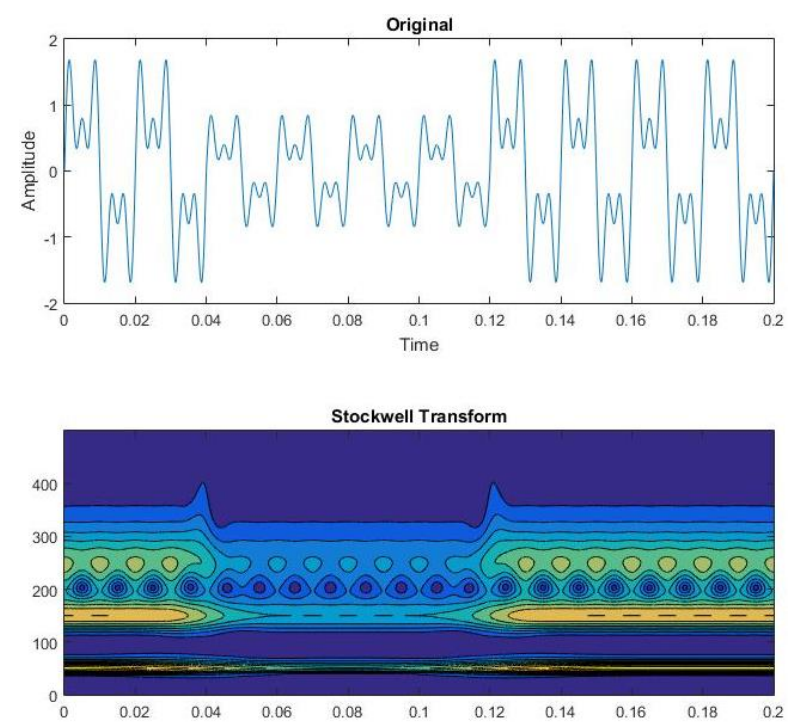

Figure 13. voltage sag signal with the $3 \mathrm{rd}$ and 5 th harmonic added and S-transform
The properties of the voltage sag with harmonics signal derived from the S-transform are given in Figure 14. From this amplitude-time graph, the range in which the voltage drops are observed. The presence of harmonics of $150 \mathrm{~Hz}$. and $250 \mathrm{~Hz}$. is obtained from the frequency time graph. The range in which voltage starts to drop and ends is seen from the graph of the geometric property. In the standard deviation graph, which is the prominent feature in the detection of harmonics, harmonics can be observed.

Based on these properties, the range in which the voltage rises are clearly seen on the amplitude time graph. The frequency values in the signal are determined as $50 \mathrm{~Hz}, 150 \mathrm{~Hz}$ and $250 \mathrm{~Hz}$ in the frequency time graph.

As it can be seen in the graph of the geometric feature that helps us to determine the interval where the voltage starts to rise and ends, it started in the 3rd period and ended in the 6th Period. In the standard deviation graph, the observed fluctuations reveal the presence of harmonics in the signal.
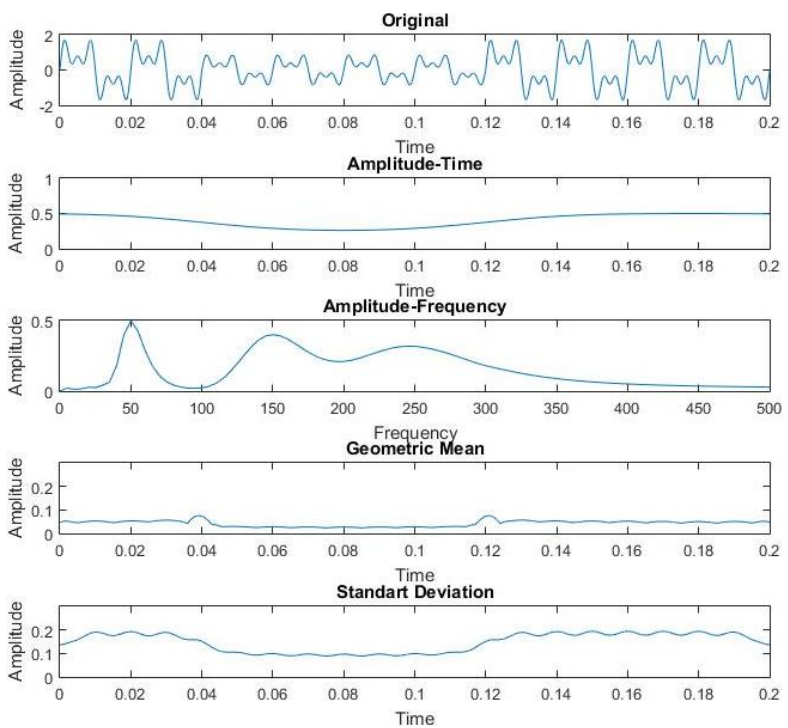

Figure 14. Properties obtained from the S-transform of the $3 \mathrm{rd}$ and 5th harmonic added voltage sag signal

\subsubsection{Voltage Swell with Harmonics}

The 10-period signal contains the 3rd and 5th harmonics, as well as the voltage swell during the 2nd and 6th periods and the S-transform is given in Figure15 .

The characteristics of the voltage swell with harmonics signal are given in Figure-16. Based on these properties, the range in which the voltage rises are clearly seen on the amplitude time graph. The frequency values in the signal are determined as $50 \mathrm{~Hz}, 150 \mathrm{~Hz}$ and $250 \mathrm{~Hz}$ in the frequency time graph. As it can be seen in the graph of the geometric feature that helps us to determine the interval where the voltage starts to rise and ends, it started in the 3rd period and ended in the 6th Period. In the standard deviation graph, the observed 
fluctuations reveal the presence of harmonics in the signal.
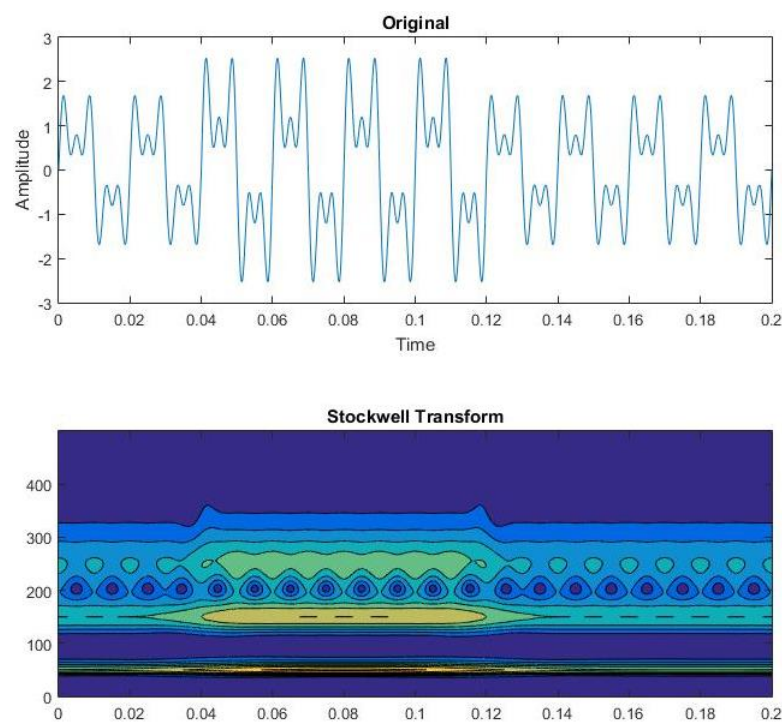

Figure 15. Voltage swell signal with the $3 \mathrm{rd}$ and 5th harmonic added and S-transform
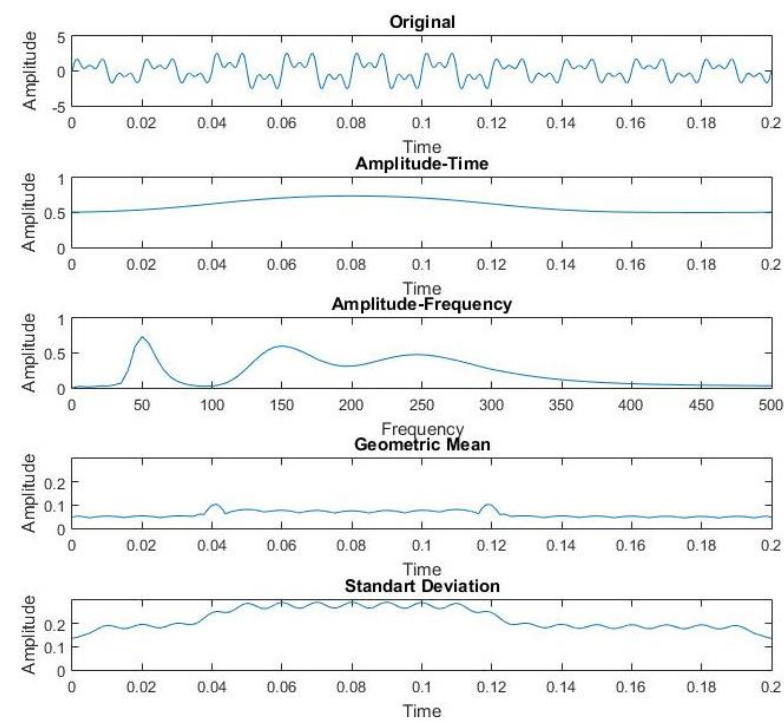

Figure 16. Properties obtained from the S-transform of the 3 rd and 5th harmonic added voltage swell signal

As it can be seen in the graph of the geometric feature that helps us to determine the interval where the voltage starts to rise and ends, it started in the 3 rd period and ended in the 6th Period.
In the standard deviation graph, the observed fluctuations reveal the presence of harmonics in the signal.

\section{Test and Discussion}

\subsection{Classification of Signals with Support Vector Machines}

Eight types of signal whose properties are obtained by using $\mathrm{S}$-transform is classified with support vector machines. Classification is made using the Quadratic SVM and one-to-one method in the Classification Learner Toolbox in MATLAB. Table 1 shows the labels of the disturbances.

Table 1. Class of PQ Events

\begin{tabular}{ll}
\hline PQD & Class Label \\
\hline Pure Sine & Distrubance1 \\
Voltage Sag & Distrubance2 \\
Voltage Swell & Distrubance3 \\
Flicker & Distrubance4 \\
Transient & Distrubance5 \\
Voltage with Harmonics & Distrubance6 \\
Voltage Sag with Harmonics & Distrubance7 \\
Voltage Swell with Harmonics & Distrubance8 \\
\hline
\end{tabular}

In Table 2, the success numbers and success percentages of the classification test data performed with SVM are given. Confusion matrix is given in Figure 17.

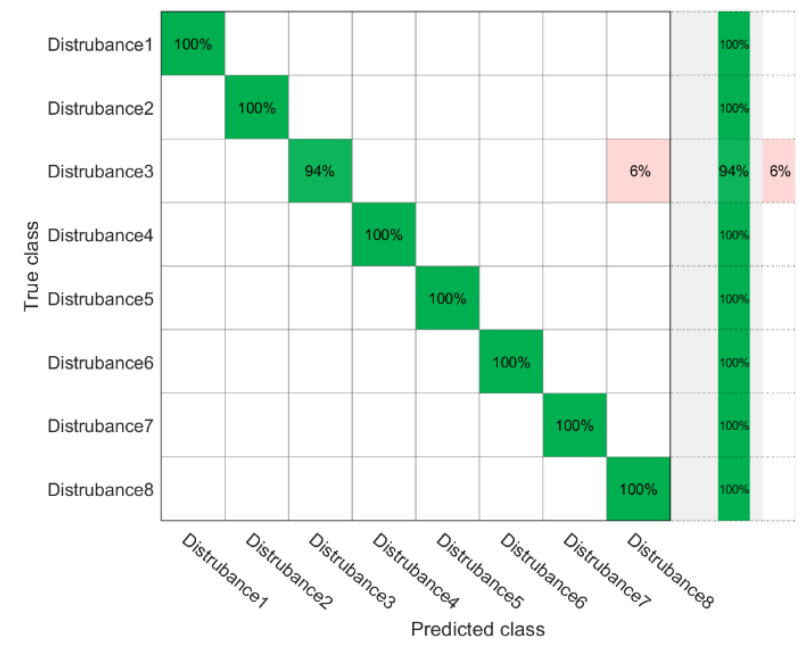

Figure 17. Confusion matrix for SVM.

Table 2. Numbers and percentages of success as a result of training

\begin{tabular}{lllll}
\hline Classes & Total Tested & Successful & Unsuccessful & Performance Percentage \\
\hline Distrubance1 & 16 & 16 & 0 & $\% 100$ \\
Distrubance2 & 16 & 16 & 0 & $\% 100$ \\
Distrubance3 & 16 & 15 & 1 & $\% 94$ \\
Distrubance4 & 16 & 16 & 0 & $\% 100$ \\
Distrubance5 & 16 & 16 & 0 & $\% 100$ \\
Distrubance6 & 16 & 16 & 0 & $\% 100$ \\
Distrubance7 & 16 & 16 & 0 & $\% 100$ \\
Distrubance8 & 16 & 16 & 0 & \\
\hline
\end{tabular}


Total performance was $99.2 \%$. Pure sine, voltage sag, flicker, voltage with harmonics, voltage sag with harmonics and voltage swell with harmonics can be estimated as $100 \%$. Only one of the test data is perceived as voltage with harmonics while voltage swell.

\subsection{Classification of Signals with Artificial Neural Networks}

In this study, the architecture of the proposed ANN is selected from the MATLAB-Neural Network Toolbox and consists of an input layer with 900 inputs, a hidden layer with 10 neurons, and an output layer with a neuron as shown in Figure 18. The number of neurons and hidden layers depends on the problem and is determined by trial and error until a target performance is achieved (Greche et al., 2017).

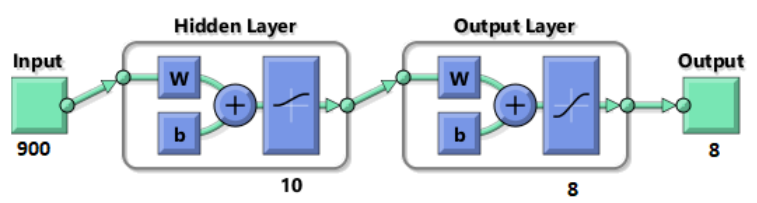

Figure 18. Two-layer feed-forward neural network architecture

The formulated network is trained with a total of 640 samples of 80 different samples per 8 disturbance classes. The number of samples of the ANN classifier for training, validation and testing is randomly selected and is given in Table 3.
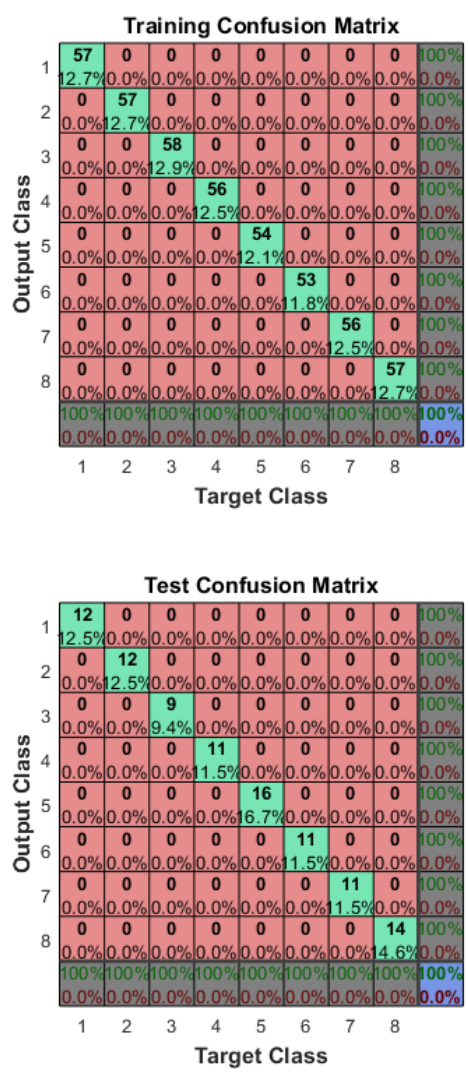

Table 3. Number of samples for training, validation and testing

\begin{tabular}{lll}
\hline Method & \%Samples & Sample number \\
\hline Training & 70 & 448 \\
Validation & 15 & 96 \\
Testing & 15 & 96 \\
Method & $\%$ Samples & Sample number \\
\hline
\end{tabular}

As the training algorithm, Scaled Conjugate Gradient back propagation training algorithm is chosen. The reason is that this algorithm takes up less memory. The training automatically stops when generalization stops healing, as shown by the increase in error (MSE) in the mean square root of validation samples.

In Figure 19, 100\% recognition performance in the confusion matrix of training, validation and test indicates that training performs well. ANN is trained with $100 \%$ accuracy and tested with $100 \%$ accuracy. This ratio is considered to be quite successful and sensitive. When the effectiveness of the applied method and the success of the results are taken into consideration, it can be concluded that the aim of this study has been achieved.

If the results are obtained less than $100 \%$, during the training process, each layer's weight can be updated by a function called optimizer. The optimizer shows better performance in computational efficiency with advantages such as aigh precision solution and quick convergence (Ruder, 2016).
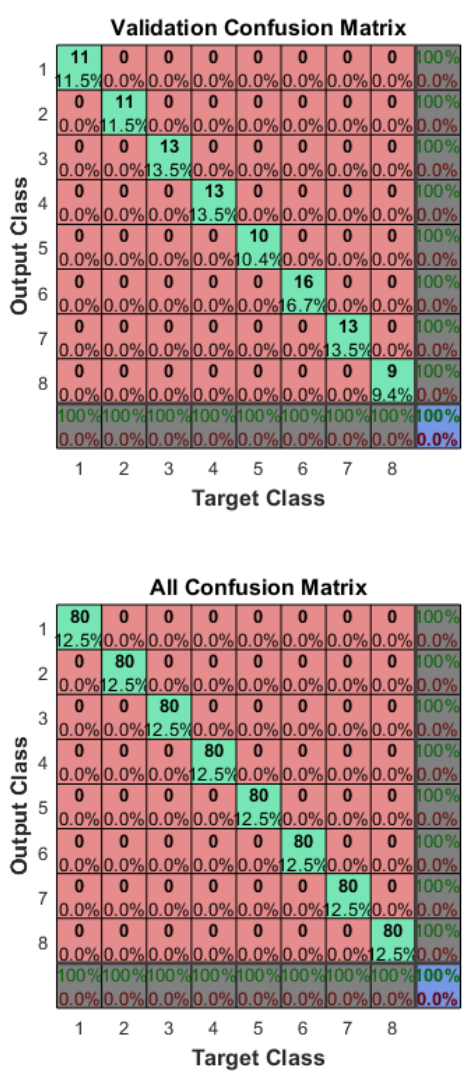

Figure 19. Confusion Matrix for ANN 


\section{Conclusions}

In this study, seven signal distortions have been produced in MATLAB environment such as voltage sag, voltage swell, voltage with harmonics, transient, flicker, voltage sag with harmonics, voltage swell with harmonics for 1 signal of amplitude and frequency of $50 \mathrm{~Hz}$. The stockwell transform of a total of 8 signals was taken with the pure sine signal. A total of 4 different properties were obtained from these signals from the Stockwell transform. These; time-dependent amplitude changes of the signal, amplitude of frequency components, geometric mean and standard deviation. The graphs of these features are presented and their roles in determining each signal type are interpreted. Changes in the amplitudes of the signals are determined from the time dependent amplitude property. The frequencies of the different components in the signal are determined from the frequency amplitudes. The properties of the changes in the amplitude of the signal are determined by using the geometric mean. In the standard deviation feature, periodic distortions such as harmonics are observed.

In the case of voltage sag and voltage swell disturbances, inferences are made from the amplitudetime graph about the voltage sag and swell. In addition, the geometric mean graph makes inferences about the time when fall and rise begin and end. In the flicker disturbance signal, the $10 \mathrm{~Hz}$ component is determined from the amplitude frequency graph. In addition, the voltage drops at the points where the flicker occurs can be observed from the amplitude time graph. When flicker occurs, it is determined by the geometric mean. In the transient distortion signal, besides the $50 \mathrm{~Hz}$ signal, the $4 \mathrm{kHz}$ signal can be observed on the amplitude-frequency graph. As with other signals, the voltage variation of the signal and the location of the change can be observed in the amplitude-time and geometric average graphs. Unlike other disturbances in the voltage with harmonics signal, there is a fluctuation in the standard deviation graph, which is used to detect the harmonics in the signal. In addition, $50 \mathrm{~Hz}$ signal and $150 \mathrm{~Hz}$ and $250 \mathrm{~Hz}$ harmonic frequencies can be observed in the amplitude frequency graph. In contrast to the voltage with harmonic signal, the voltage decreases or increase in the amplitude-time graph and the points where the voltage starts to decrease and starts to increase in the voltage sag with harmonics and voltage swell with harmonics are determined.

High quality results can be obtained if training and testing is performed by using the classification methods obtained from this transformation. These properties are classified with SVM and ANN. As a result of the classification, decays can be estimated with $99.54 \%$ SVM and $100 \%$ ANN. Thus, both methods are successful for a strong feature extraction, and ANN gives a much better result.

Compared to other feature extraction methods, STransform contains both frequency and time information. This offers a great advantage in the feature extraction of the signals.

\section{References}

Agarwal, R. K., Hussain, I., Singh, B., 2017. Application of LMS-based NN structure for power quality enhancement in a distribution network under abnormal conditions. IEEE transactions on neural networks and learning systems, 29(5), pp. 1598-1607.

Azam, M. S., Tu, F., Pattipati, K. R., Karanam, R., 2004. A dependency model-based approach for identifying and evaluating power quality problems. IEEE Transactions on power delivery, 19(3), pp. 1154-1166.

Chilukuri MV, Dash PK., 2004. Multiresolution S-transformbased fuzzy recognition system for power quality events. IEEE Trans Power Delivery. 19(1), pp. 323-330.

Choudhary, B. (2021). An advanced genetic algorithm with improved support vector machine for multi-class classification of real power quality events. Electric Power Systems Research, 191, 106879.

Cortes, C., Vapnik, V., 1995. Support-vector networks. Machine learning, 20(3), pp. 273-297.

Dharavath, R., Raglend, I. J., Manmohan, A., 2017. Implementation of solar PV-Battery storage with DVR for power quality improvement. In 2017 Innovations in Power and Advanced Computing Technologies (i-PACT), pp. 1-5.

Elango, M. K., Loganathan,K., 2016.Classification of power quality disturbances using Stockwell Transform and Back Propagation algorithm. Emerging Technological Trends (ICETT), International Conference on. IEEE.

Gaing, Z. L., 2004. Wavelet-based neural network for power disturbance recognition and classification. IEEE transactions on power delivery, 19(4), pp. 1560-1568.

Greche, L., Es-Sbai, N., Lavendelis, E., 2017. Histogram of oriented gradient and multi-layer feed forward neural network for facial expression identification. In 2017 International Conference on Control, Automation and Diagnosis (ICCAD), pp. 333-337.

Ingale, R., 2014. Harmonic analysis using FFT and STFT. International Journal of Signal Processing, Image Processing and Pattern Recognition, 7(4), pp. 345-362.

Karasu, S., Başkan, S., 2016. Classification of power quality disturbances by using ensemble technique. In 2016 24th Signal Processing and Communication Application Conference (SIU), pp. 529-532.

Liang, C., Teng, Z., Li, J., Yao, W., Wang, L., He, Q., Hu, S., 2021. Improved S-Transform for Time-Frequency Analysis for Power Quality Disturbances. IEEE Transactions on Power Delivery.

Mahela, O. P., Shaik, A. G., 2016. Recognition of power quality disturbances using S-transform and rule-based decision tree. In 2016 IEEE 1st International Conference on Power Electronics, Intelligent Control and Energy Systems (ICPEICES), pp. 1-6.

Mishra, A. K., Ray, P. K., Mallick, R. K., Mohanty, A., \& Das, S. R., 2021. Adaptive fuzzy controlled hybrid shunt active power filter for power quality enhancement. Neural Computing and Applications, 33(5), pp. 1435-1452. 
Ozgonenel, O., Yalcin, T., Guney, I., Kurt, U., 2013. A new classification for power quality events in distribution systems. Electric Power Systems Research, 95, pp. 192199.

Poisson, O., Rioual, P., Meunier, M., 2000. Detection and measurement of power quality disturbances using wavelet transform. IEEE transactions on Power Delivery, 15(3), pp. 1039-1044.

Raj, S., Phani, T. K., Dalei, J., 2016. Power quality analysis using modified S-transform on ARM processor. In 2016 Sixth International Symposium on Embedded Computing and System Design (ISED) (pp. 166-170). IEEE.

Ruder, S., 2016. An overview of gradient descent optimization algorithms. arXiv preprint arXiv:1609.04747.

Saxena, D., Singh, S. N., Verma, K. S., Singh, S. K., 2014. HHT-based classification of composite power quality events. International Journal of Energy Sector Management.

Shamachurn, H., 2019. Assessing the performance of a modified S-transform with probabilistic neural network, support vector machine and nearest neighbour classifiers for single and multiple power quality disturbances identification. Neural Computing and Applications, 31(4), pp. 1041-1060.

Sindi, H., Nour, M., Rawa, M., Öztürk, Ș., Polat, K. (2021). An adaptive deep learning framework to classify unknown composite power quality event using known single power quality events. Expert Systems with Applications, 178, 115023.

Singh, B., Al-Haddad, K., Chandra, A., 1999. A review of active filters for power quality improvement. IEEE transactions on industrial electronics, 46(5), pp. 960-971.

Singh, U., Singh, S. N., 2017. Application of fractional Fourier transform for classification of power quality disturbances. IET Science, Measurement \& Technology, 11(1), pp. 67-76.

Tao, W., Yin, S., Ding, M., Li, C., Yu, N., Bao, X., Guo, J., 2013. Classification of power quality disturbance signals based on S-transform and HHT. In Proceedings of the 32nd Chinese Control Conference, pp. 3639-3644.

Thirumala, K., Prasad, M. S., Jain, T., Umarikar, A. C., 2016. Tunable-Q wavelet transform and dual multiclass SVM for online automatic detection of power quality disturbances. IEEE Transactions on Smart Grid, 9(4), pp. 3018-3028.

Wang, S., Chen, H., 2019. A novel deep learning method for the classification of power quality disturbances using deep convolutional neural network. Applied energy, 235, pp. 1126-1140.

Yoo, J. H., Shin, S. K., Park, J. Y., Cho, S. H., 2015. Advanced railway power quality detecting algorithm using a combined TEO and STFT method. Journal of Electrical Engineering and Technology, 10(6), pp. 2442-2447.

Zhao, Z., Wang, S., Zhang, W., Xie, Y., 2016. A novel automatic modulation classification method based on Stockwell-transform and energy entropy for underwater acoustic signals. In 2016 IEEE international conference on signal processing, communications and computing (ICSPCC), pp. 1-6. 